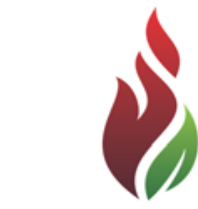

SUSTENERE

Publishing Corporation

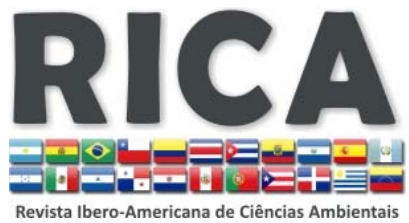

Journals Homepage:

www.sustenere.co/journals

\section{A EDUCAÇÃO AMBIENTAL NA PRÁTICA DOCENTE: ENSINO INFANTIL E FUNDAMENTAL NA ESCOLA MUNICIPAL FRANCISCA MENDES DA SILVA - SANTANA DO MATOS (RN)}

\section{RESUMO}

O presente artigo tem o objetivo de identificar se a Escola Francisca Mendes da Silva - Santana do Matos/RN trabalha com Educação Ambiental, e qual a sua importância na formação de alunos do ensino infantil e fundamental, a partir da análise das políticas educacionais e do papel da escola e dos professores neste processo. O trabalho aborda a ação e perspectiva dos professores a cerca da ação sociocultural e a responsabilidade de estimular a participação comunitária e cidadã. A ação político-ideológico é uma manifestação crítica da realidade para promover alternativas em relação à problemática ambiental, e para a ação pedagógica na elaboração de modelos didáticos alternativos, capazes de promover diferentes tipos de aprendizagens e estimular novos comportamentos em relação ao contexto ambiental. Para a construção do trabalho, tomou como base à etnografia, um tipo de pesquisa social com base empírica que busca a resolução de um problema coletivo, sendo que de alguma forma os pesquisadores e os participantes representativos da situação ou problema estão envolvidos de modo cooperativo ou participativo. Desse modo foi aplicado um questionário semiestruturado, ao qual o entrevistado (a) teve a liberdade de responder sem a interferência do entrevistador. Dos dez (10) professores que trabalham e atuam no ensino infantil e fundamental da referida escola, apenas oito (8) responderam o questionário. Diante do que foi observado durante o período de construção deste trabalho constatou-se que são muitas as maneiras de se trabalhar a Educação Ambiental na escola em estudo basta que à iniciativa surja dos professores, sendo que não necessariamente de maneira formal, mas no cotidiano da sala de aula, aproveitando que as crianças são facilmente seduzidas pelo meio que as cerca.

PALAVRAS-CHAVES: Educação Ambiental; Degradação Ambiental;

Transversalidade.

\section{ENVIRONMENTAL EDUCATION IN TEACHING PRACTICE: TEACHING CHILDREN AND FUNDAMENTAL IN MUNICIPAL SCHOOL FRANCISCA MENDES DA SILVA - SANTANA DO MATOS (RN)}

\section{ABSTRACT}

This article aims to identify whether Francisca Mendes Silva School - Santana do Matos / RN works with environmental education, and what is its importance in the training of students in kindergarten and elementary teaching about environmental issues, from the analysis of educational policies and the role schools and teachers in this process. This article discusses the action and perspective of teachers about the sociocultural action and responsibility to encourage community participation and citizen ; Political and ideological action as a form of expression, criticism of reality to promote alternatives with respect to environmental issues, and action teaching the elaboration of alternative didactic models, able to promote different types of learning and encourage new behaviors in relation to the environmental context. For the construction of this article, was based on the ethnographic, is a type of social research evidence base that seeks to solve a collective problem, and somehow the researchers and the participants representative of the situation or problem are involved in cooperative mode or participatory. Thus a semi-structured questionnaire was applied, to which the respondent had the freedom to respond without interference from the interviewer. Of the ten (10) working teachers and act in kindergarten and elementary school, only eight (8) responded. Faced with what was observed during the construction period of this study that there are many ways to work Environmental Education in school under study, just leave it to the initiative of teachers, and not necessarily in a formal way, but in the everyday the classroom leveraging of the children are easily seduced by the medium that surrounds them.

KEYWORDS: Environmental Education; Environmental Degradation; Transversality.
Revista Ibero-Americana de

Ciências Ambientais, Aquidabã,

v.5, n.2, Jun, Jul, Ago, Set, Out, Nov 2014.

ISSN 2179-6858

SECTION: Articles

TOPIC: Educação Ambiental

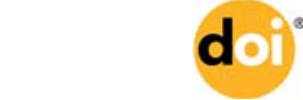

DOI: 10.6008/SPC2179-6858.2014.002.0003

Vanessa Tainara da Cunha

Universidade Federal Rural do Semi-Árido, Brasil http://lattes.cnpq.br/3302251128340486 tainara.vanessa@yahoo.com

Valeria Tatiany da Cunha Universidade Federal Rural do Semi-Árido, Brasil http://lattes.cnpq.br/4826423988828349 valeriatatiany@yahoo.com.br

Andrezza Grasielly Costa Universidade Federal Rural do Semi-Árido, Brasil http://lattes.cnpq.br/4536779734693311 andrezza grasielly@hotmail.com

Emanoela Magna da Cunha Universidade Federal Rural do Semi-Árido, Brasil http://lattes.cnpq.br/0759817284962400 emanoelacunha@hotmail.com

Ludimilla Carvalho Serafim de Oliveira

Universidade Federal Rural do Semi-Árido, Brasil http://lattes.cnpq.br/2217661943948945 ludimilla@ufersa.edu.br

Received: 28/03/2014

Approved: $15 / 11 / 2014$

Reviewed anonymously in the process of blind peer.

Referencing this:

CUNHA, V. T.; CUNHA, V. T.; COSTA, A. G.; CUNHA, E. M.; OLIVEIRA, L. C. S.. A educação ambiental na prática docente: ensino infantil e fundamental na escola municipal Francisca Mendes da Silva - Santana do Matos (RN). Revista Ibero-Americana de Ciências Ambientais, Aquidabã, v.5, n.2, p.29-37, 2014. DOI: http://dx.doi.org/10.6008/SPC21796858.2014 .002 .0003 


\section{INTRODUÇÃO}

A degradação ambiental ao longo dos anos vem aumentando, devido o uso desordenado dos recursos naturais, uso este que vem contribuindo para uns dos maiores problemas que a humanidade vem enfrentando nos últimos anos, cuja gravidade é amplamente conhecida pelo que representa para a vida de todas as espécies, incluindo, portanto, para a própria sobrevivência do ser humano. Visando isso a educação ambiental surge como uma solução para as degradações ambientais, partindo do princípio que o conhecimento muda e sensibiliza o cidadão (LOPES, 2011).

Mas infelizmente não é o que averiguamos nos dias atuais, pois conforme Martins (2009) para o funcionamento da educação ambiental é necessário que haja a sua atuação como um mecanismo favorável ao meio de cada cidadão, e que cada um repense a respeito de suas práticas ambientais e que se reeduquem. A educação ambiental não deve ser apenas formulada de ideais ilusórias, incapazes de ser alcançados, mas sim, de opiniões críticas que levem os cidadãos a repensar suas atitudes, dessa forma levando-o a criarem uma consciência de transformação social.

Tendo em vista a necessidade de trabalhar educação ambiental, aplicou-se na Escola Francisca Mendes da Silva questionários baseados na metodologia de pesquisa-ação, que de acordo com Thiollent (1986), é um tipo de pesquisa social com base empírica que busca a resolução de um problema coletivo e no qual os pesquisadores e os participantes representativos da situação ou problema estão envolvidos de modo cooperativo ou participativo.

Encontrou-se na escola problemas relacionado à forma de como trabalhar a educação ambiental com crianças do ensino infantil e fundamental. Tendo em vista essa dificuldade é importante buscar nas demais instituições algum tipo de trabalho relacionado ao assunto para estimular as crianças sobre a importância da sustentabilidade no meio em que vivemos, seja ele ambiental econômico e/ou social; ao contrário do encontrado na instituição em questão, onde as crianças não possuem esse contato com a educação ambiental e nem com o meio ambiente e acaba retido a salas de aula ou pátios com solo de cimento, o que dificulta sua interação com o meio ambiente. Partindo do princípio que as crianças, em geral, são muito curiosas e gostam do contato com a natureza, de olhar como as formigas se comportam, de abrir as torneiras e brincar com a água, fazem festa no pátio de areia, querem subir nas árvores, enfim, procuram por cada canto de sua escola um vestígio de natureza com a qual possam ter contato, torna-se primordial que estes conhecimentos sejam passados, levando em consideração que eles vão atuar como agentes multiplicadores (SCARDUA, 2009).

Diante desse contexto, algumas novas tarefas passam a colocar à escola, não porque esta seja a única instância responsável pela educação, mas por ser a instituição que desenvolve uma prática educativa planejada e sistemática durante um período contínuo e extenso na vida dos alunos. E também porque é reconhecida pela sociedade como a instituição da aprendizagem. 
Diante disso o objetivo do presente trabalho foi identificar se a Escola Francisca Mendes da Silva - Santana do Matos/RN trabalha com Educação Ambiental, e qual a importância na formação de alunos do ensino infantil e fundamental, a partir da análise das políticas educativas e do papel da escola e dos professores neste processo.

\section{REVISÃO TEÓRICA}

\section{Degradação Ambiental}

A natureza sempre atendeu as necessidades humanas mesmo quando o homem passou a exigir mais do meio natural sendo necessário produzir além de colher, dessa forma a produção foi crescendo cada vez mais, não apenas para cessar a necessidade como também 'os desejos' da humanidade chegando ao ponto de a natureza não conseguir se restituir gerando a degradação do meio ambiente. De acordo com Marcatto (2002), o que contribuiu para a degradação ambiental foi o modelo de desenvolvimento atual que é desigual, excludente e esgotante dos recursos naturais, provocando poluição do solo, ar e água, destrói a biodiversidade animal e vegetal além do esgotamento das reservas minerais e demais recursos não renováveis.

Conforme Brasil (1981) a degradação da qualidade ambiental seria a alteração adversa das características do meio ambiente, estando extremamente ligado ao impacto ambiental, tendo em vista que a degradação surge através de um impacto, esse impacto é definido pela Resolução CONAMA 001 (1986) em seu Artigo $1^{\circ}$ como sendo qualquer alteração das propriedades físicas, químicas e biológicas do meio ambiente, causada por qualquer forma de matéria ou energia resultante das atividades humanas que, direta ou indiretamente, afetam: a saúde, a segurança e o bem-estar da população; as atividades sociais e econômicas; a biota; as condições estéticas e sanitárias do meio ambiente e a qualidade dos recursos ambientais.

Em contraposição busca-se reverter esse quadro introduzindo no dia-a-dia das pessoas conceitos e práticas de preservação ambiental, desenvolvimento sustentável, através da educação ambiental.

\section{Educação Ambiental}

A educação ambiental é um instrumento essencial para a sensibilização e persuasão da população a cerca dos problemas ambientais. Devido à mesma buscar desenvolver técnicas e métodos que facilitem a conscientização dos cidadãos sobre a gravidade dos problemas ambientais (MARCATTO, 2002).

Conforme Brasil (1999) entende-se por educação ambiental os processos por meio dos quais o indivíduo e a coletividade constroem valores sociais, conhecimentos, habilidades, atitudes 
e competências voltadas para a conservação do meio ambiente, bem de uso comum do povo, essencial à sadia qualidade de vida e sua sustentabilidade.

Em busca destas mudanças na educação ambiental conforme o Ministério da Educação (2007), o Brasil através das diretrizes e políticas públicas vem incentivando a Educação Ambiental nas escolas desde a segunda metade dos anos 90 . Dessa forma o processo de expansão da Educação Ambiental nas escolas de ensino fundamental houve um crescimento considerado entre o ano de 2001 e 2004, pois o número de alunos matriculados nas escolas que oferecem Educação Ambiental passou de 25,3 milhões para 32,3 milhões, o que corresponde a uma taxa de crescimento de $28 \%$ em comparação ao ano de 2001.

Isso só é possível porque de acordo com Brasil (1996) a educação abrange os processos formativos que se desenvolvem na vida familiar, na convivência humana, no trabalho, nas instituições de ensino e pesquisa, nos movimentos sociais e organizações da sociedade civil e nas manifestações culturais.

Visando isso o Art. $3^{\circ}$ da referida Lei, é bem claro quando diz que o ensino deverá ser ministrado com base nos seguintes princípios: de igualdade de condições para o acesso e permanência na escola; liberdade de aprender, ensinar, pesquisar e divulgar a cultura, o pensamento, a arte e o saber; respeito à liberdade e apreço à tolerância; valorização da experiência extraescolar; coexistência de instituições públicas e privadas de ensino; vinculação entre a educação escolar, o trabalho e as práticas sociais; gestão democrática do ensino público, na forma desta Lei e da legislação dos sistemas de ensino; garantia de padrão de qualidade entre outros.

É preciso que os professores conheçam o tema e a linguagem ambientalista, pois só assim é possível criar pontos de conexão e debate em torno do assunto, considerando-a em toda sua complexidade. Todavia, esta problemática é complexificada por Rodríguez (2003) quando ele afirma que, a Educação Ambiental ocorra de forma coerente e eficaz nas salas de aula, sendo necessário sanar as seguintes questões básicas: Em primeiro lugar, que se produza uma verdadeira integração da Educação Ambiental como dimensão transversal dos objetivos curriculares, impregnando a instrução e a aprendizagem nas diferentes matérias ou áreas, de forma efetiva e planificada, superando assim, sua frequente existência como atividade desconexa ou pontual. Para isso é preciso abordar a definição de uma clara proposta do sentido da educação ambiental como transversal, assim como do planejamento metodológico mais idôneo para seu desenvolvimento como tal; Em segundo lugar, também parece preciso partir de um "modelo básico" de Educação Ambiental, a fim de promover o esclarecimento de alguns traços fundamentais da mesma, pelo menos desde o ponto de vista conceitual; E em terceiro lugar, dado que a Educação Ambiental pretende o desenvolvimento de atitudes e valores que podem levar, definitivamente, a propostas de ação, parece necessário dispor de critérios que permitam avaliar este possível desenvolvimento do alunado. 
Portanto, seria interessante que todos os professores procurassem seguir essas questões em busca de um melhor desenvolvimento da educação ambiental com os seus alunos.

\section{METODOLOGIA}

O trabalho foi realizado em junho de 2013, na Escola Francisca Mendes da Silva, localizada no município de Santana dos Matos (RN).

O município de Santana dos Matos (RN) como ilustrado na Figura 1, possui uma população de 13.688 habitantes, com área territorial de $1.419 \mathrm{Km}^{2}$, tendo como bioma a Caatinga (IBGE, 2013). Sendo que a mesma situa-se na mesorregião Central Potiguar e na microrregião Serra de Santana, limitando-se com os municípios de Fernando Pedroza, Angicos, Itajá, Lagoa Nova, São Vicente, Tenente Laurentino Cruz, Florânia, Jucurutu, Bodó, Cerro Corá e São Rafael (CPRM, 2005).

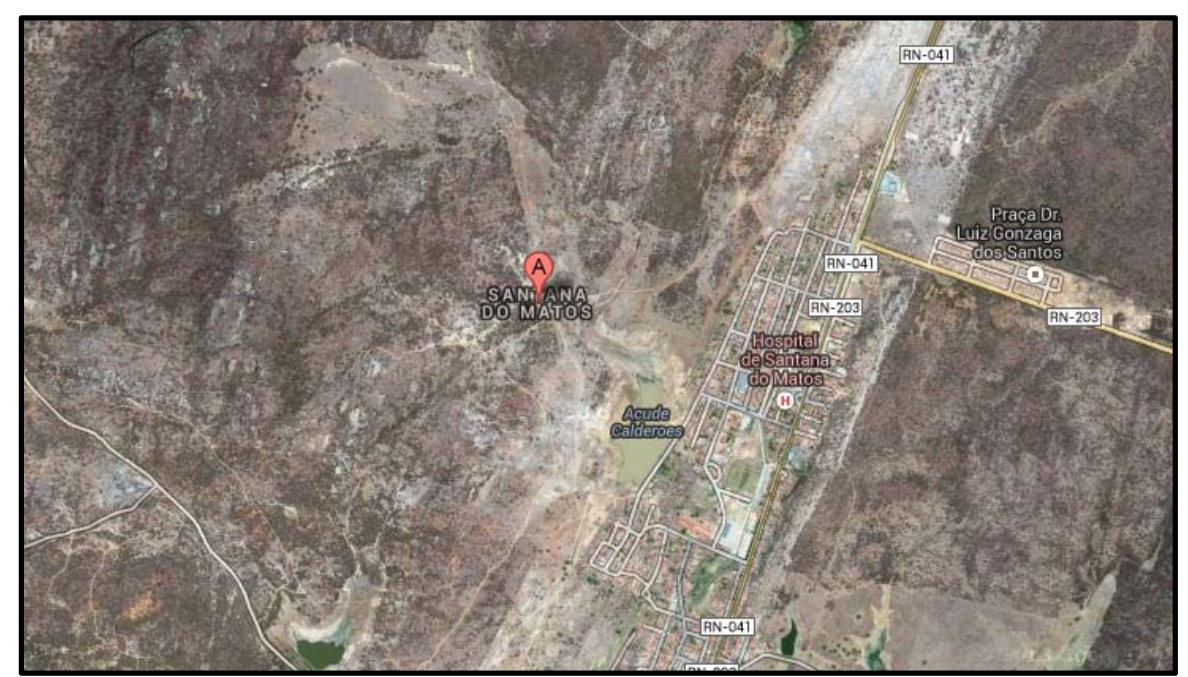

Figura 1: Localização Através de Imagem de Satelite da Cidade de Santana do Matos (RN).

Fonte: Google Maps.

Para a construção do trabalho, tomou como base a etnografia, tipo de pesquisa social com base empírica que busca a resolução de um problema coletivo, sendo que de alguma forma os pesquisadores e os participantes representativos da situação ou problema estão envolvidos de modo cooperativo ou participativo. Desse modo foi aplicado um questionário semiestruturado, ao qual o entrevistado (a) teve a liberdade de responder sem a interferência do entrevistador. Dos dez (10) professores que trabalha e atuam no ensino infantil e fundamental da referida escola, só oito (8) responderam. O objetivo da pesquisa foi de conhecer a metodologia dos professores e se os mesmos trabalhavam a educação ambiental, e de que forma eles faziam isso com os alunos.

Vale ressaltar que foi realizada a análise e tratamento dos dados coletados numa abordagem tanto quantitativos como qualitativos, com ênfase no conteúdo dos formulários e com o referencial teórico que fundamenta o estudo proposto. A coleta de dados também foi realizada através das pesquisas bibliográficas e de campo e análise documental. 


\section{RESULTADOS}

O estudo realizado com o corpo docente da Escola Municipal Francisca Mendes da Silva (EMFMS), iniciou-se com uma abordagem, em relação à faixa etária dos professores. Analisandose os dados percebe-se que dos $100 \%$ dos entrevistados, $88 \%$ encontram-se acima dos 40 anos, enquanto apenas $12 \%$ representam os professores que estão com no máximo 20 anos (este número é decorrente de contratos feitos pela prefeitura de Santana dos Matos. Ao contrário da faixa etária dos professore da referida escola, os educadores do Programa Educação de Jovens e Adultos (EJA) atuam na rede de ensino estadual da grande São Paulo a faixa etária é diversificada, pois conforme Bedoya e Teixeira (2008) dos 21 entrevistados 19,0\% têm entre 21 e 30 anos, $42,9 \%$ têm entre 31 e 40 anos, $28,6 \%$ têm entre de 41 a 50 anos e 9,5\% têm entre 51 e 60 anos.

Nos dias atuais, nas diversas localidades do país e do mundo, por diferentes meios de comunicação vem sendo discutidas campanhas educativas, tentando conscientizar a população a respeito da importância da educação ambiental. Nessa perspectiva, foi investigado o grau de instrução dos mesmos, fato este que chamou bastante atenção tendo em vista que 50\% possuem apenas o ensino médio, $25 \%$ estão cursando graduação, $13 \%$ especialização, $12 \%$ ensino superior completo como ilustra o Gráfico 1. Já de acordo com o Ministério da Educação (2009), existem em todo o país 119.323 docentes (6,3\%), que concluíram o ensino fundamental ou o ensino médio mas não têm a habilitação para o exercício do magistério. Sendo que a maior parte destes professores cursou apenas o ensino fundamental, com uma percentagem de $0,8 \%$ do total, que corresponde a 15.982 docentes, sendo que na região Nordeste é onde se encontra em maior percentagem.

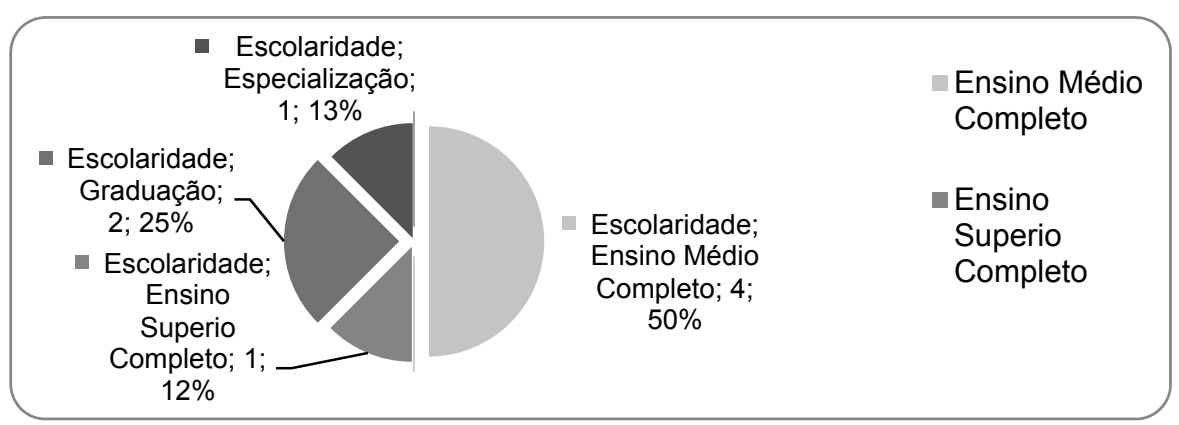

Gráfico 1: Grau de Instrução dos Entrevistados.

$\mathrm{Na}$ oportunidade também foi questionado o tempo de atuação destes profissionais, na instituição de ensino, onde $88 \%$ estão a mais de dez anos, $12 \%$ a menos de um ano, decorrentes de contratos. Pode-se observar que o tempo de atuação dos mesmos encontra-se apenas entre dois períodos, porém vale salientar que demonstram conhecimentos ainda que rudimentares a respeito da educação ambiental, mas é de comum acordo que a temática deve ser inclusa nas atividades desempenhadas ao longo da formação dos discentes. 
Também se questionou aos professores sobre a importância de trabalhar educação ambiental no ensino infantil e fundamental, com unanimidade as respostas foram positivas, eles afirmaram que era importante trabalhar educação ambiental, isso fica implícito nas respostas de cada um como, por exemplo, um dos professores responderam que: 'É importante trabalhar Educação Ambiental porque ela contribui para a formação de cidadãos conscientes, aptos para decidirem e atuarem na realidade socioambiental de um modo comprometido com a vida, com o bem estar de cada um da sociedade, local e global'. Na cidade de Carlópolis (PR) não é diferente, onde $80 \%$ dos participantes consideram importante trabalhar a Educação Ambiental com as crianças e, apenas $20 \%$ a não consideram importante.

Em sequência foi questionado se eles como professores trabalhavam Educação Ambiental com os seus alunos, e todos responderam que sim, uns responderam que era através de textos, músicas, brincadeiras, esta metodologia é utilizada na educação infantil, outros frisaram, que ensinam através da conscientização, sensibilização dos alunos, mostrando a realidade, decorrente da ação antrópica. Quando perguntado aos professores se existem conteúdo relacionado à educação ambiental, $87 \%$ disseram que sim, só que os conteúdos citados pelos mesmos estão relacionados com o que vem nos livros didáticos, e os mesmos não vem com nada especifico, só vem falando da importância da higiene, da água, ou seja, fica muito difícil o aluno ter um conhecimento de sustentabilidade, de educação ambiental entre outros, e 13\% disseram que não trabalhavam educação ambiental, este percentual é decorrente do professor está iniciando agora sua vida acadêmica.

Partindo do princípio que na Escola trabalha Educação Ambiental, foi questionado aos referidos professores se os livros didáticos disponíveis na mesma trazem conteúdos relacionados ao tema em questão, visando isso o Gráfico 2 mostra que os livros abordam de alguma forma as questões ambientais, sendo que esta abordagem é mais frequente nas disciplinas de ciências com $31 \%$ em seguida geografia com $30 \%$, história $17 \%$, biologia com $13 \%$ e a disciplina de português com apenas $9 \%$.

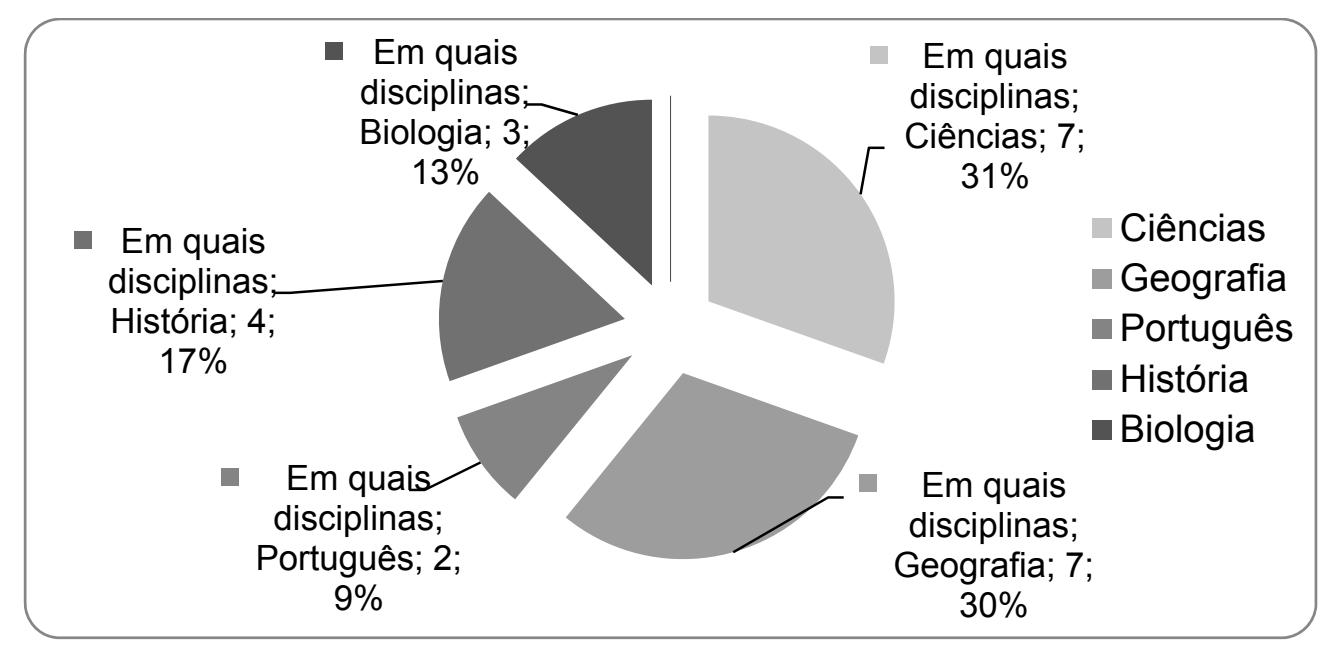

Gráfico 2: Em quais disciplinas, os livros didáticos trazem conteúdos relacionados à educação ambiental. 
Nos dias atuais não basta só trabalhar educação ambiental nos livros didáticos, pois para os professores da escola em estudo é preciso fazer bem mais que isso, isso é notório quando em algumas de suas falas eles retratam 'que as pessoas têm que tomar consciência que ela mesma faz parte desse contexto, e por isso ela é também responsável pelo futuro do nosso planeta', pois se cada um pensasse que é o responsável pelo seu ato no planeta com certeza os impactos ambientais estariam bem menor. Também foi perguntado aos mesmos se é importante ensinar desde criança a educação ambiental 100\% disseram sim.

Durante a pesquisa foi questionado se a Escola abordava projetos na área de educação ambiental, e conforme os dados obtidos pode-se perceber que $75 \%$ dos entrevistados responderam que sim, os outros $25 \%$ restantes disseram que não há projetos desenvolvidos na área ambiental. Alguns professores responderam que eram sobre o lixo, e preservação de árvores, preservação dos rios, meio ambiente entre outros, mas na realidade estes são assuntos abordados em sala e não possui nem um projeto que seja trabalhado referente a estes temas.

Foi questionado se eles quanto professores consideram importante a implantação da temática ambiental na grade curricular, e com um percentual de $87 \%$ dos entrevistados responderam que sim, alguns dos professores frisaram que seria interessante que existisse uma disciplina apenas referente às questões ambientais, pois os alunos com certeza aprenderiam desde sedo os problemas, causas e medidas de conservação e preservação do meio ambiente, e apenas $13 \%$ responderam que não é importante.

Apesar de todos os problemas decorrentes dos impactos ambientais causados pelo mau uso dos recursos naturais, a Escola em estudo possui um ponto positivo, pois com uma porcentagem de $87 \%$ disseram que o local é arborizado, graças a uma gestão anterior que plantou árvores no local, e com apenas $13 \%$ disseram que a escola não era arborizada.

A arborização não só na escola, mas nos demais locais são fundamentais, levando em consideração que além de ajudar na conservação do meio ambiente ainda contribui, refletindo, absorvendo e transmitindo radiação solar, melhorando a temperatura do ar no ambiente urbano, sem falar que elas absorvem ruídos, promovem a qualidade do sono, melhorando assim a qualidade de vida.

\section{CONCLUSÕES}

A proposta desse estudo foi de identificar o grau de conhecimento dos professores a cerca das questões ambientais (educação ambiental, sustentabilidade entre outros). Diante do que foi observado durante o período de construção deste trabalho constatou-se que são muitas as maneiras de se trabalhar a Educação Ambiental na escola, basta que a iniciativa surja dos professores, sendo que não necessariamente de maneira formal, mas no cotidiano da sala de aula, aproveitando que as crianças são facilmente seduzidas pelo meio que as cerca, mas é importante que isso não ocorra só na Escola em estudo, mas de forma global, ou seja, que seja trabalhada em todas as escolas de educação infantil e fundamental. 
Visando isso a junção de Educação Ambiental e do ensino infantil e fundamental torna-se imprescindível para se criar uma nova geração que conheça e tenha compreensão para com a natureza, tratando-a com respeito, reconhecendo-se parte integrante dela. Mesmo os livros didáticos trazendo conteúdos relacionados ao meio ambiente conforme a pesquisa, isso não é o suficiente, é necessário que os professores abordem temas mais específicos, relacionados às questões ambientais englobando a realidade dos alunos, mas para que isso aconteça torna-se necessário que eles tenham tido uma formação adequada na área. Talvez se todos os integrantes que constituem o ensino do país tomassem consciência da importância da educação ambiental o mundo da educação tomaria proporções maiores e melhores.

\section{REFERÊNCIAS}

BEDOYA, M. J. A.; TEIXEIRA, R. R. P.. Perfil dos professores da educação de jovens e adultos. Athena Revista Científica de Educação, v.10, n.10, p.63-75, 2008.

BRASIL. Lei $n^{\circ}$ 6.938, de 31 de agosto de 1981. Dispõe sobre a Política Nacional do Meio Ambiente, seus fins e mecanismos de formulação e aplicação, e dá outras providências. Brasília, 31 Ago 1981.

BRASIL. Lei $n^{\circ}$ 9.394, de 20 de dezembro de 1996. Estabelece as diretrizes e bases da educação nacional. Brasília, 20 Dez 1996.

BRASIL. Lei $n^{\circ}$ 9.795, de 27 de abril de 1999. Dispõe sobre a educação ambiental, institui a Política Nacional de Educação Ambiental e dá outras providências. Brasília, 27 Abr 1999.

BRASIL. Resolução CONAMA n 1, de 23 de janeiro de 1986. Dispõe sobre critérios básicas e diretrizes gerais para a avaliação de impacto. Brasília, 23 Jan 1986.

LOPES, T. C. S.. Educação ambiental como estratégia de sensibilização ambiental em uma escola de ensino médio, Angicos/RN. TCC (Graduação) - Universidade Federal Rural do Semi-Árido, Rio Grande do Norte, 2011.

MARCATTO, C.. Educação ambiental: conceitos e princípios. Belo Horizonte: FEAM, 2002.

MARTINS, N.. A educação ambiental na educação infantil. TCC (Graduação) - Curso de Pedagogia, Universidade Federal De São Carlos, São Carlos, 2009.

MINISTÉRIO DA EDUCAÇÃO. Estudo exploratório sobre o professor brasileiro com base nos resultados do Censo Escolar da Educação Básica 2007. Brasília: INEP, 2009.

MINISTÉRIO DA EDUCAÇÃO. Educação ambiental: aprendizes de sustentabilidade. Brasília: INEP, 2007.

SCARDUA, V. M.. Crianças e meio ambiente: a importância da educação ambiental na educação infantil. Revista Face, Vila Velha, n.3, p.57-64, 2009.

SILVA, M. L.. A educação ambiental no ensino superior brasileiro: do panorama nacional às concepções de alunos (as) de pedagogia na Amazônia. Revista Eletrônica do Mestrado em Educação Ambiental, n.5. especial, p.1-16, 2013. 